\title{
THE DETERMINATION OF THE EXTENT OF FAULTING WITH APPLICATION TO THE LONG BEACH EARTHQUAKE*
}

\author{
By Hugo Bentofr
}

The Long Beach earthquake of March 10, 1933, produced no visible evidence to indicate the extent of faulting. The epicenter which Gutenberg ${ }^{1}$ and Wood ${ }^{2}$ located a few kilometers off the coast at Newport was determined by the arrival times of the first longitudinal waves. It therefore indicates solely the point at which faulting originated. It offers no information on the extent of faulting nor on the area from which maximum destructive energy radiated. The distribution of destruction was such as to suggest that faulting extended northwest along the Inglewood fault in the direction of Long Beach. Long Beach and Compton, distant 18 and 25 miles, respectively, from the epicenter, exhibited severe damage. With liberal allowances for poor construetion and bad ground, it is difficult to believe that an earthquake of such small magnitude could produce damage of such severity at such large distances from the epicenter unless faulting extended a substantial distance toward Long Beach.

A rather crude though definite instrumental indication of extension of faulting is furnished by comparison of seismic wave periods of the principal shock with those of aftershocks. At Pasadena, the principal shock was recorded on a modified torsion seismograph having a period of 10 seconds, critical damping, and a magnification of 4 . Aftershocks were recorded on a torsion seismograph having substantially the same constants with the exception of the magnification, which was 800, approximately. It was clear from a casual inspection of the seismograms that the principal shock exhibited much longer periods than those of the aftershocks. This effect indicates that in the principal shock the fault displacement either took place more slowly or extended an appreciably greater distance. Since the first alternative makes the power of the principal shock less than that of the aftershocks, it must be assumed that fault extension is the cause of the longer periods.

A more precise method of determining the extent of faulting can be derived from the mechanism of faulting as given by the elastic rebound theory. Referring to figure $1 a$, we may suppose that in the neighborhood of a vertical fault habitually experiencing horizontal slip, indicated by a heavy line, a series of perpendicular lines is laid out on the ground at a time when the region is in an unstrained condition. With the passing of time, strains are set up, and the

* This work was done under the auspices of the Carnegie Institution of Washington, Seismological Research. The paper was presented at the annual meeting of the Seismological Society of America, April 12-13, 1935. Manuscript received for publication December 15,1937 .

2 B. Gutenberg, "Das Seismological Laboratory in Pasadena," Ergebnisse der Kosmischen Physik, Band 2, p. 236 (1934).

2 Harry O. Wood, "Preliminary Report on the Long Beach Earthquake," Bull. Seism. Soc. Am., 23:43-56 (1933). 
consequent configuration of the region is given by figure $1 b$. As the strains increase further, there comes a time when the stress at some point exceeds the cohesive strength of the fault and in consequence the two fault surfaces slide by each other (see fig. 2). This initial movement generates two seismic waves as shown in figure 2, where the outer circle represents the front of a compressional wave and the inner circle represents the front of a slower shear wave. The immediate effect of the longitudinal wave is to increase the existing strains at the

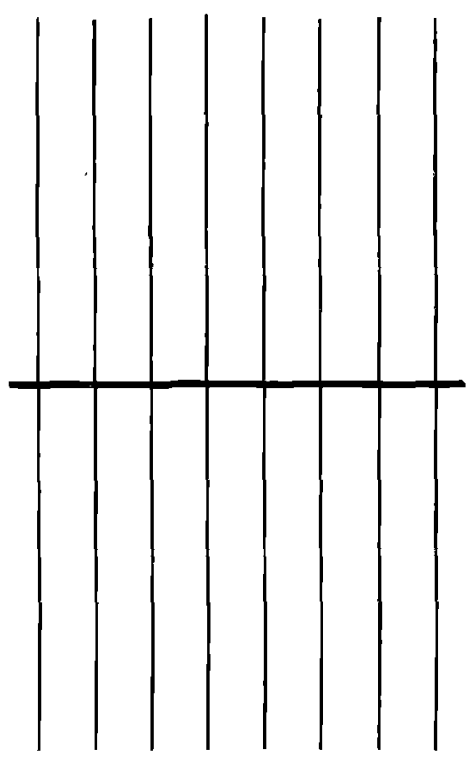

$a$

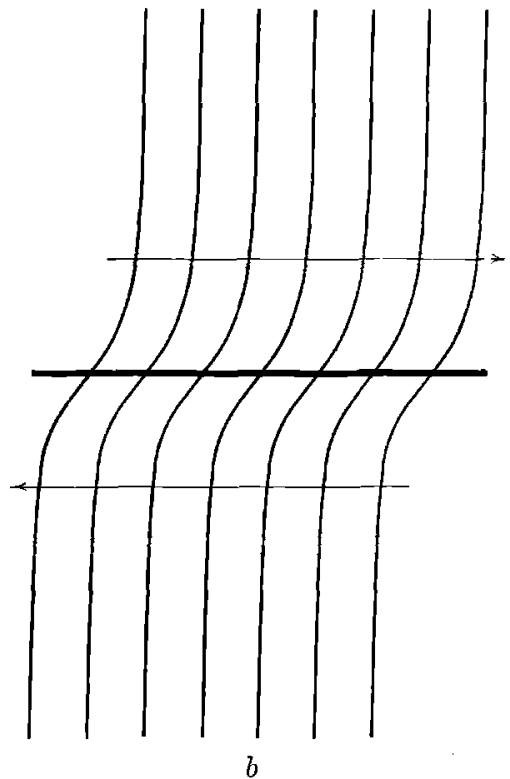

Fig. 1. Idealized graphic representation of faulting. $a$. Region in an unstrained condition b. Same region as affected by strains.

neighboring points along the fault. This effect is evident in figure 2 where the arrows indicate the direction of motion of the ground particles in the wave front of the initial longitudinal wave. When the additional stress due to the wave is sufficient to raise the total stress to the breaking point a wave of faulting is propagated along the fault. The faulting velocity must necessarily be less than the longitudinal wave velocity, since the wave front is not rectangular and in consequence a finite time is required for the incremental stress to build up to the slipping value. Since the faulting velocity does not differ greatly from the wave velocity, the elementary waves generated from successive slipping points are approximately in phase and consequently their effects are cumulative. Under such conditions, the incremental stress generated by the waves may be sufficient to cause the fault movement to overshoot the equilibrium position in the region of the end point, and thus to leave the structure in a state of strain 
opposite in direction to that of the original tectonic strain. Evidence will be given later to indicate that this was the condition following the Long Beach earthquake.

If the mechanies of faulting just described is correct the observed events at a given station may be predicted with the help of the diagram in figure 3 , where $F$ is the focus, $O$ the observing station, $A$ the length of the active segment of the fault, $B$ the distance from the station to the end point of the fault segment,

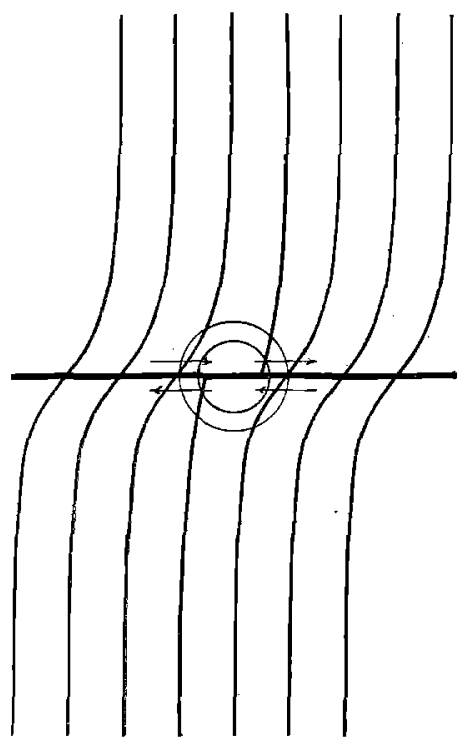

Fig. 2

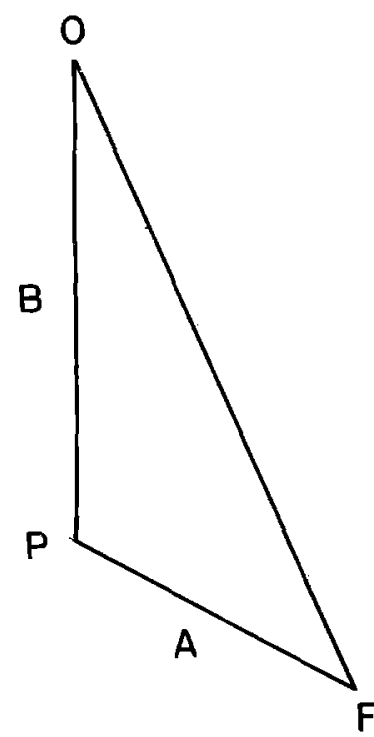

Fig. 3

Fig. 2. Diagram showing movement of waves generated by faulting.

Fig. 3. Diagram for use in calculating wave movements.

and $\mathrm{OF}$ the distance from the focus to the station. We assume that the earthquake begins at $\mathrm{F}$ at the time zero. A wave of faulting is generated and proceeds along the fault with a velocity of $V_{f}$. The faulting movement will therefore arrive at the end point $\mathrm{P}$ at a time $t_{1}=A / V_{f}$. The shear wave which is generated at the end point arrives at $\mathrm{O}$, the observing station, after an interval $t_{2}=B / V_{s}$, from the time it started, where $V_{s}$ is the velocity of shear waves. The total apparent travel time of this shear wave is therefore

$$
t_{s}=t_{1}+t_{2}=A / V_{f}+B / V_{s}
$$

Under favorable conditions, this wave may arrive at the observing station earlier than the initial shear wave from the focus, for although its total path is longer than that of the direct wave, it has, in effect, traveled part of the way along the fault as a faulting impulse with a velocity which is higher than that of 
the normal wave. This conclusion was pointed out by Reid. ${ }^{3}$ Dr. Gutenberg has made the suggestion that this early arrival of $\mathbf{S}$ may explain, at least in part, Jeffreys' statement that in near earthquakes $\mathbf{P}$ appears to originate several seconds later than S. (See, e.g., The Earth, 2d ed., p. 98.) If the observed travel time is less than that of the direct wave, equation (1) can be used to

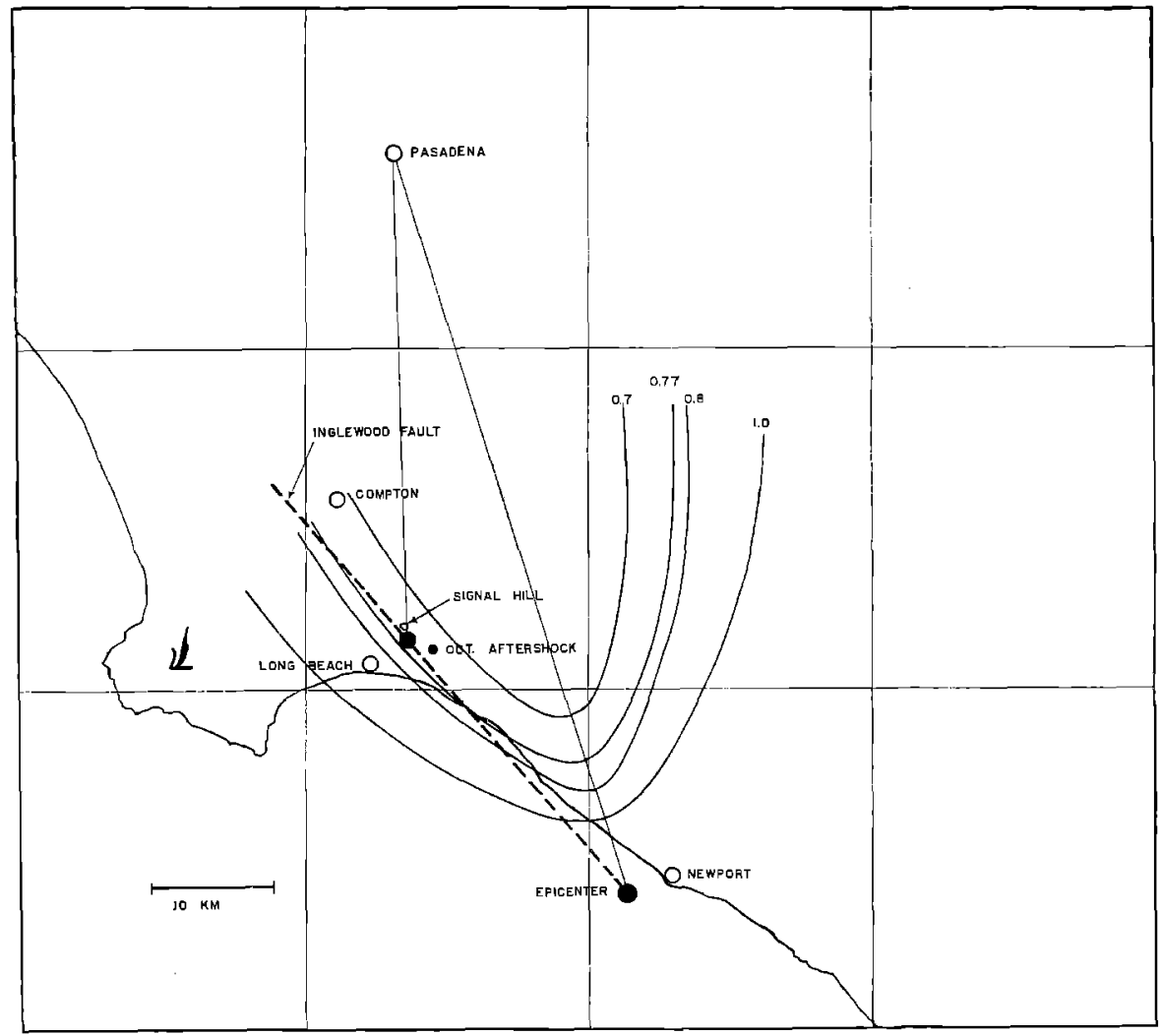

Fig. 4. Index map of the region of the Long Beach earthquake.

calculate $A$, the extent of faulting. The simplest procedure is to plot the family of curves determined by equation (1) on a map of the region, using the observed value of $t_{s}$ with faulting velocity as a parameter. The intersection of a given curve with the fault gives the extent of faulting for the assumed faulting velocity. The minimum extent of faulting is given by the curve which represents a faulting velocity equal to $V_{p}$, the velocity of longitudinal waves. As the assumed faulting velocity is reduced, the corresponding curves become smaller until finally a limiting value is reached at which the curve is just tangent to the

${ }^{3}$ H. F. Reid, "The Starting Points of Earthquake Vibrations," Bull. Seism. Soc. Am., $8: 82(1918)$. 
fault. With further decrease in faulting velocity the curves no longer intersect the fault. The limiting tangent point represents therefore the maximum extent of faulting. Figure 4 represents the region of the Long Beach earthquake. The Inglewood fault is indicated by the heavy dotted line. The focus is drawn with coördinates $\lambda=117^{\circ} 58^{\prime} \mathrm{W}$, and $\phi=33^{\circ} 36^{\prime} \mathrm{N}$. The corresponding focal distance from Pasadena is $64.4 \mathrm{~km}$. and the travel time of the first longitudinal wave is accordingly $64.4 / 5.55=11.6$ sec. The $\mathrm{S}-\mathrm{P}$ time interval measured on the strong-motion seismogram is $7.3 \mathrm{sec}$. This includes a correction of $+0.4 \mathrm{sec}$. determined by Wood and Richter as the time taken by the lamp filament to heat up to recording temperature from comparison with other Pasadena seismograms. The travel time of the first $S$ arrival is thus $11.6+7.3=18.9 \mathrm{sec}$. This may be compared with the computed travel time $64.4 / 3.22=20$ sec. for the direct wave from the focus. The first $S$ arrival was therefore $1.1 \mathrm{sec}$. early. The curves are graphs of equation (1) with $t_{s}=18.9 \mathrm{sec}$. The curve designated with the number 1 is computed with a faulting velocity equal to the velocity of longitudinal waves, $5.55 \mathrm{~km} / \mathrm{sec}$. The other curves were constructed using faulting velocities as indicated. The limiting value is approximately $0.75 \mathrm{~V}=4.2 \mathrm{~km} / \mathrm{sec}$. The corresponding maximum limit for the extent of faulting is indicated by the larger dot near Signal Hill. Although it is known that the faulting velocity is less than the velocity of longitudinal waves, the precise value is not given in this method. Consequently the extent of faulting is determined only with respect to upper and lower limits. However, with reference to the Long Beach earthquake, there is evidence to indicate that the upper limit represents the actual limit of faulting.

The most reliable evidence comes from observation on aftershocks. Recent determinations of epicenters by Wood and Richter ${ }^{4}$ have shown that the aftershocks have been almost uniformly distributed throughout the length of the segment indicated by the large dots. This distribution was maintained from the very first hours following the principal shock. Few, if any, aftershocks occurred beyond the segment in either direction. Assuming that the observed distribution of aftershocks represents the actual extent of faulting, the curves of figure 4 indicate that the average faulting velocity for the principal shock was $0.75 V_{p}$ or $4.2 \mathrm{~km} / \mathrm{sec}$.

The largest aftershock occurred on October 2 . It caused some minor damage. Its epicenter as determined by Wood and Richter is shown on the map of figure 4. The direction of movement in this shock as indicated by the seismograms was opposite to that of the principal shock. It is reasonable to believe therefore that during the main earthquake the fault movement actually overshot the equilibrium position and that this large aftershock represented a return to equilibrium.

Further evidence respecting the extent of faulting in the Long Beach earth-

${ }^{4}$ Private communication. 
quake is supplied by some observations of Dr. Thomas Clements which were published in Science. ${ }^{5}$ He measured the direction of fall of tombstones in several cemeteries situated in the destructive region. In general, he found that for a given cemetery the stones fell in two favored directions at right angles to each other. The number which fell in one direction was considerably larger than the

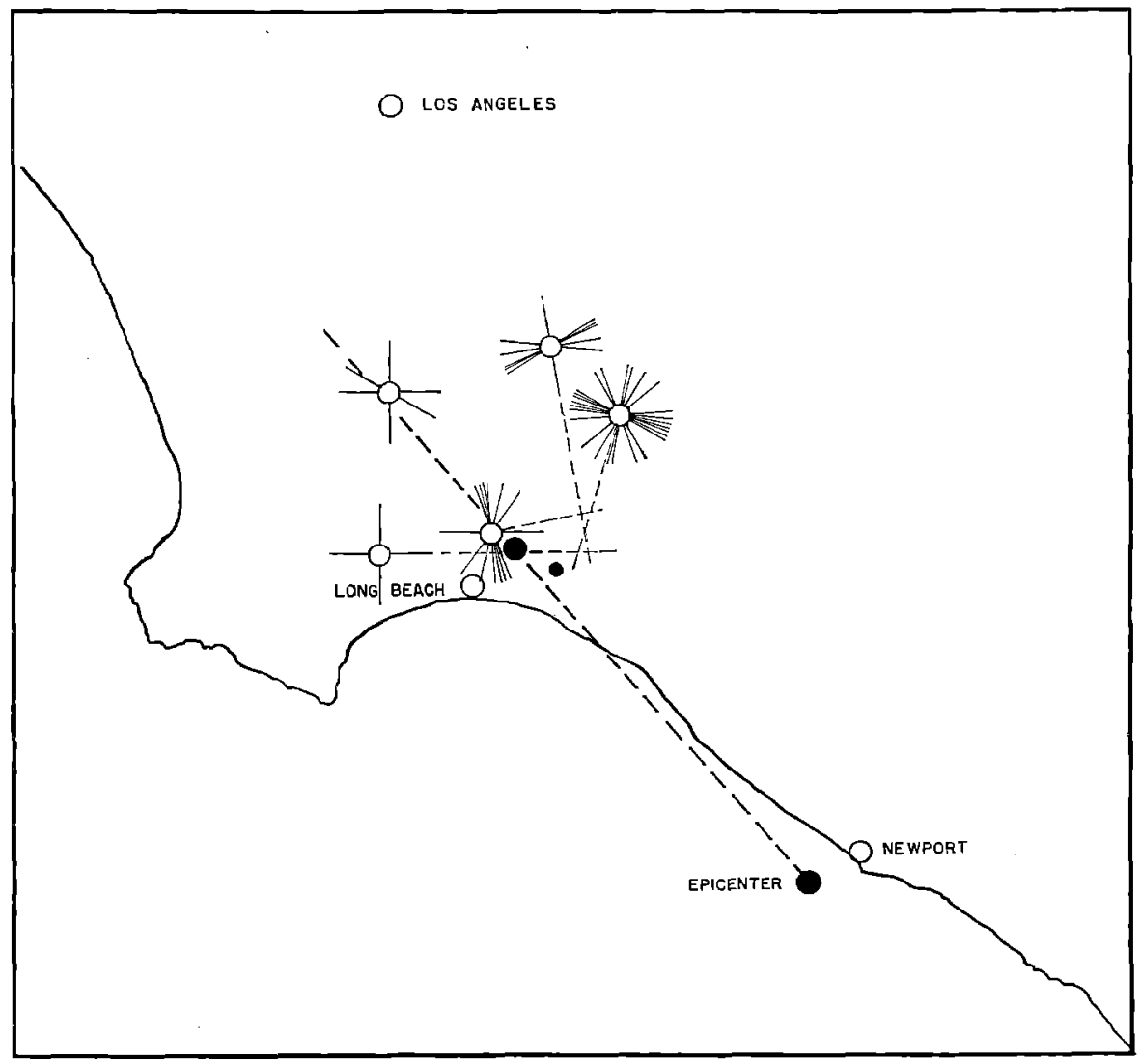

Fig. 5. Graphic representation of Clements' data.

number which fell in the other direction. Clements assumed that the epicenter of the earthquake is given by the intersection of the directions corresponding to the maximum number of falls. In other words, he assumed that the larger number of stones was overthrown by longitudinal waves. The epicenter which he found in this manner, he located near Compton. It is common experience, however, that the transverse waves of earthquakes exhibit larger amplitudes than the longitudinal waves. It is to be expected therefore that transverse 5 Thomas Clements, "Notes on the Fall of Columns During the Long Beach Earthquake," Science, 78:100-101 (1933). 
waves cause the larger number of falls. On this assumption, Clements' data give results in substantial agreement with those given in the preceding paragraphs. Clements' observations are shown in figure 5. The circles with the intersecting lines represent the five cemeteries which he studied. Each line represents the direction of fall of one or more stones. The thin dotted lines are drawn at right angles to the more common direction of fall and represent the azimuths of the source at the various cemeteries on the assumption that transverse waves cause the larger number of falls. It is clear that all but one of the cemeteries indicate directions in excellent agreement with the results of this paper. The one discordant cemetery is on the projection of the fault and would therefore receive much less energy in the transverse-wave form. It cannot be expected to indicate true directions.

Recently Clements ${ }^{6}$ reported a series of experiments on the fall of columns which he interprets as substantiating evidence for his contention concerning the direction of fall of columns during earthquakes. In these experiments nearly all the columns fell parallel to the direction of the epicenter. Dynamite blasts served as sources of seismic energy. His columns were all within 50 feet of the focus. It is generally understood that at these small distances seismic energy liberated by a blast is confined chiefly to longitudinal waves. On the other hand, in tectonic earthquakes a large fraction of energy must necessarily be released in the form of shear waves. It would seem unsafe, therefore, to apply the results of blast observations to the interpretation of earthquake phenomena of this kind.

\section{Summary}

An instrumental method is described for the determination of the extent of faulting in a given earthquake which depends upon the early arrival of S. If the faulting velocity is known, the exact extent is determined; otherwise, only upper and lower limits are given. Conversely, if the extent of faulting is known from field or other evidence, the faulting velocity is determined.

The development given refers to a vertical fault exhibiting horizontal displacement, or, more generally, to a fault in which the displacement is parallel to the direction of extension. When the displacement is perpendicular to the direction of extension, as in a simple vertical fault, the faulting impulse is propagated by shear waves. For this condition the shear waves from the end point can never arrive earlier than the wave from the focus. On the basis of these considerations an observed early arrival of $\mathrm{S}$ indicates that the source is a fault movement in which the displacement is parallel to the direction of extension. In general this would refer to a horizontal extension of fault slip, although for observers in the vicinity of the epicenter it could refer to a vertical fault movement originating in the depths and propagating upward.

"Thomas Clements, "Experiments on the Fall of Columns," Bull. Seism. Soc. Am., $26: 229-234$ (1936). 
In applying this method to the Long Beach earthquake, the available evidence indicates that faulting extended from the focus approximately to Signal Hill, a distance of $27 \mathrm{~km}$., with a faulting speed of approximately $4.2 \mathrm{~km} / \mathrm{sec}$.

[Balch Gradtate School of the Geological Sciences, California Institute of Technology, Pasadena,

Contribdtion No. 218] 